\title{
Subsea controls future proofing: A systems strategy embracing obsolescence management
}

\author{
Nimi Abili*, Raluchukwu Onwuzuluigbo and Fuat Kara \\ School of Applied Science, Cranfield University, Cranfield, Bedfordshire, MK43 OAL, UK
}

\begin{abstract}
The increasing world energy demands for enhanced oil and gas recovery in the offshore industry has led to new subsea technology developments with increased system functionality. Technologies such as subsea processing and instrumentations for subsea control data acquisition place a greater demand on bandwidth, power and capacity. Therefore, the legacy controls system becomes obsolete and proves unsustainable in supporting the increased functionality placed on it by the new subsea technologies. With the fast evolution of electronics, the replacement of the core components of the control system when they fail becomes difficult as they are no longer being produced or supported by the original component manufacturers (OCM).

The present paper explores the different strategies in addressing obsolescence on the subsea controls system for offshore field developments.
\end{abstract}

Keywords: legacy control systems, proactive strategy, diminishing manufacturing sources and material shortages (DMSMS), open system architecture, resolution cost metrics, obsolescence management

\begin{tabular}{|ll|}
\hline Acronym list \\
\hline BOPD & barrels of oil per day \\
CAPEX & capital expenditure \\
COTS & commercial off the shelf \\
DMEA & defence microelectronics activity \\
DMSMS & diminishing manufacturing source and material \\
& shortage \\
DOD & US Department of Defense \\
EPU & electrical power unit \\
GIDEP & Government Industry Data Exchange Program \\
IOR & increased oil recovery \\
MPFM & multiphase flow meter \\
NRE & non-recurring engineering \\
OCM & original component manufacturer \\
OEM & original equipment manufacturer \\
OPEX & operating expenditure \\
SCM & subsea control module \\
SEM & subsea electronic module \\
SPCS & subsea production control system \\
SPU & subsea processing unit \\
SSBI & subsea separation boosting and injection \\
\hline
\end{tabular}

* Contact author. E-mail address: n.i.abili@cranfield.ac.uk
1. Introduction

The offshore oil and gas industry has deployed innovative technologies to address challenges encountered both in brownfield and greenfield development over two decades in order to maximise production and increase recovery of reservoirs. Technologies, such as subsea processing and multiphase flow meter (MPFM) with the data acquisition, have been at the front burner in providing solutions ranging from general flow assurance issues to enhanced recovery (McClimans and Fantoft, 2006; Rasmussen, 2003; Chiesa and Eriksen, 2000). Such technological developments, however, represent a significant technological requirement in terms of data processing capacity, high power demand, high speed control and increased system functionality (Midttveit et al., 2010; Neri and Falk, 2006).

Studies of the subsea controls system (the brainbox of the subsea production system) equally show a corresponding technological advancement. This has occurred in order to enable a control system platform capable of supporting the high power, high speed, increased data-handling capacity and reliability demand placed by the new technologies (Gall et al., 2002; Broadbent, 2010).

The trend has seen the multiplex electro-hydraulic system presently having a proven record success over the direct electro-hydraulic and pilot sequence hydraulic system. Furthermore, the all-electric control system considered as the control system of the future has demonstrated greater capacity and functionality (Abicht and Akker, 2011; Mackenzie, 2011). The implication is that subsea components have to evolve to adapt to these new technologies.

Apart from the observed changes in some critical component of the subsea production system owing to underlying drive to develop new technologies, other external factors have also contributed, such as safety requirement, legislation, market and the disposition of the original component manufacturers (OCM) (Cahill, 2009; Adrain, 2008). 
One such equipment that is most significantly affected by the external factors is the subsea electronic module (SEM), a key element of the subsea control module (SCM). The SEM is basically made of semiconductors and microchips and their markets are largely controlled by the computer, communication and consumer sector (Sandborn, 2007b; Feldman and Sandborn, 2007). As the subsea industry is not a significant player in the electronic industry, it has to flow with the pace of the electronic market evolution, especially as the product life cycle of this type of electronics is much shorter than the subsea control system life cycle (Cretenet, 2004).

Thus the overall effect of the changes owing to new technology development, electronic market and external factor influences is that legacy system becomes obsolete and proves challenging for ageing fields (Frantzen et al., 2011; Beedle and Stansfield, 2010; Saul, 2006). This is a significant problem facing offshore operators, as many are discovering that they are unable to execute like-for-like replacement of failed equipment because it is no longer in the market.

This poses a very serious challenge to system availability during component or equipment failure (Baker, 2011; Energy Institute, 2011). Shut-in time is extended which implies loss of production and, in some extreme cases, will result in complete failure of asset. Ultimately, such possibilities have necessitated the need for obsolescence solution to enable the integration of legacy systems with future proof systems and thus reduce the occurrence of obsolescence or its impact on subsea production facilities.

The present paper evaluates the reactive strategy of inaction until obsolete equipment fails, compared to a proactive strategy of implementing obsolescence monitoring and open architecture for subsea controls future proofing. It also evaluates the impact that a proactive strategy has on operating expenditure (OPEX) and availability, proffering a cost approach to ascertain its impact economically on offshore field developments.

\section{Obsolescence}

Equipment becomes obsolete when it is no longer produced by the original equipment manufacturer (OEM), or where the technical assistance for the product has been withdrawn. Obsolescence, on the other hand, refers to the period after which the OEM discontinues further production of equipment or technical support for the given product, leading to the depletion of the remaining components or equipment (Cretenet, 2004; Baker, 2011; Energy
Institute, 2011; Ward and Sohns, 2011). This is also known as diminishing manufacturing sources and material shortages (DMSMS) (Sandborn, 2007b; Shearer and Tomczykowski, 2001; Shaw et al., 2010; Tomczykowski, 2001; McDermott et al., 1999). This implies that like-for-like replacement for the product will become impossible.

\subsection{Reasons for obsolescence}

A study carried out within the offshore industry revealed that there are several reasons why obsolescence can occur for a given product or material (Cretenet, 2004; Aker Solutions, 2009). Some of the causes include:

- technological development, where new technology replaces the existing technology;

- new functionality and requirement on the system;

- innovative life cycles of components that are shorter than the system life cycle;

- the OEM no longer finding the product viable to produce;

- the OEM being no longer in business for any reason;

- changes in legislation within the industry, such as restriction of hazardous substance and waste electrical and electronic equipment.

\subsection{Electronic obsolescence}

Different types of electronic components experience obsolescence; some are more critical and well pronounced. According to a survey conducted by the US Government Industry Data Exchange Program (GIDEP), it was observed that DMSMS is a major problem especially for the electronics and microcircuit components (Shearer and Tomczykowski, 2001; Tomczykowski, 2001).

The increasing emphasis on using commercial off-the-shelf (COTS) items by many industries including the offshore oil and gas industry, however, has some challenges. The OEMs are more sensitive to their commercial customers and (to a lesser extent) the military, while the subsea industries have just a small market share of the COTS market (Tomczykowski, 2001; Josias et al., 2004; Condra et al., 1997). Although the demand is considered huge for the subsea industry, it is no match to the demand levels within the communication industry, among others, where the OCMs rarely pay attention to backward compatibility (Baker, 2011; Energy Institute, 2011).

Fig 1 shows a typical GIDEP DMSMS notice trend for both electronic and non-electronic items produced from 1997 to 2000 with consequential obsolescence impact on the subsea industry. The focus, however, is on the notices placed on electronic 


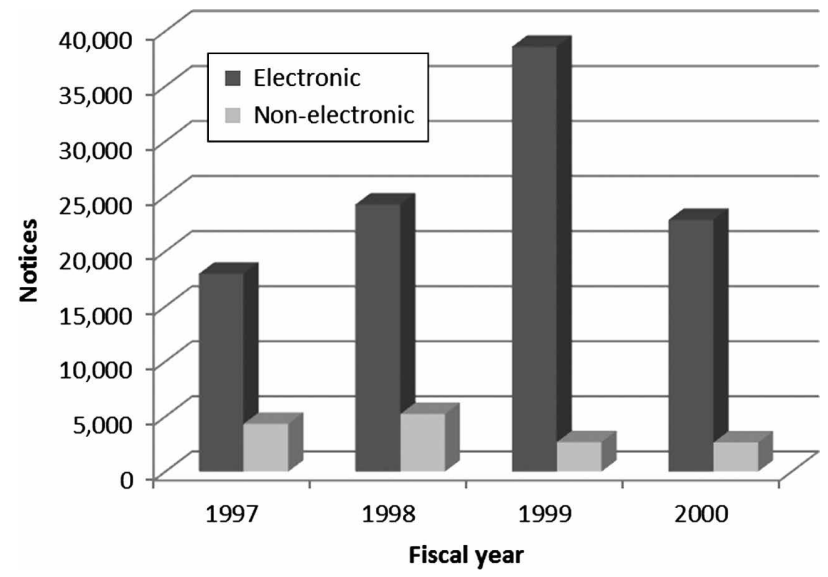

Fig 1: DMSMS notices (Source: Tomczykowski, 2001)

items, and it is believed that this trend, though over 10 years ago, would have similar significant track records for electronic items to date as a result of electronic evolution.

\subsection{Obsolescence and the subsea production system}

In the UK alone, status of fields still producing from 1975 to 2012 based on data from the Department of Energy and Climate Change (2012) are indicated in Fig 2. It clearly shows that within the period under review, some fields have been producing for 37 years from time of first oil and still have capacity for life extension. For such fields obsolescence is inevitable and becomes more prominent when they need to be extended without an earlier plan of accommodating such extension with new technology for increased oil recovery.

Some of the systems that are most likely to experience obsolescence in the subsea production system are mainly the subsea production control system (SPCS). In addition, some complex subsea systems are also likely to experience obsolescence such as the high integrity pressure protection system, subsea processing units (SPU) and even downhole equipment (electrical submersible pump) (Baker, 2011; Energy Institute, 2011; Lewis et al., 2009). Some of these systems are more susceptible to obsolescence than the others and therefore need more attention.

As mentioned, the SPCS is most prone to obsolescence, and the major reason for its susceptibility is the fact that its core components, which are electronics, have product life cycles that are much shorter than the subsea production life cycle, as illustrated in Fig 3 (Beedle and Stansfield, 2010; Cretenet, 2004; Solomon et al., 2000).

Among the major items in a subsea production system, the major area of concern for obsolescence management lies in the SCM (Table 1).

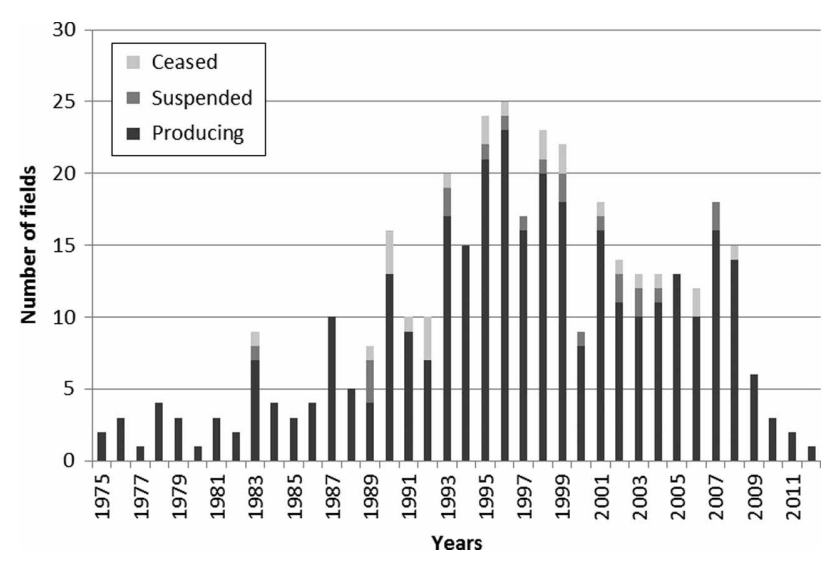

Fig 2: UK offshore oil fields producing from 1975 to 2012

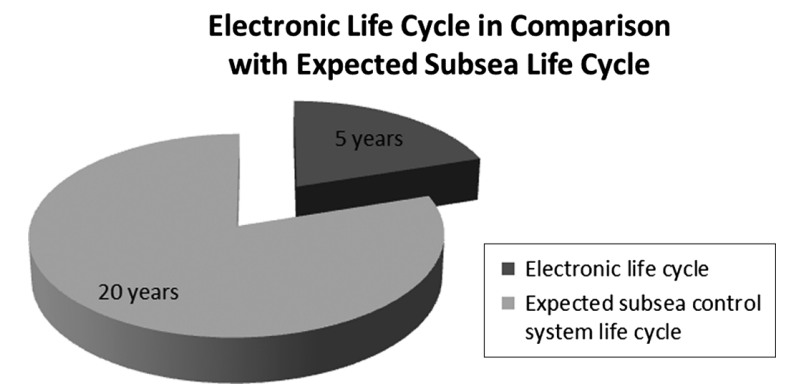

Fig 3: Electronic life cycle versus subsea control system life cycle

\subsubsection{Subsea control module obsolescence}

The SCMs are regarded as the brain box of the subsea production system and are used to operate valves as well as to monitor process instrumentation. At the heart of the SCM is the key component known as the SEM, which incorporates semiconductors and microchips. These COTS items with barely one-year product life cycles are incorporated by first-tier suppliers and inevitably make the SEMs obsolete over time (Baker, 2011; Energy Institute, 2011). Thus, this increases the frequency of irretrievability and interchangeability, with negative impact on the product life cycle and OPEX throughout the field life.

\subsubsection{Software obsolescence}

Obsolescence in electronic components (i.e. microchip, memory and programmable devices) has the tendency of affecting software programs that run them. Hardware changes can be significant to an extent that the background software can no longer support them, but often software changes cause hardware to become obsolete. However, software becomes obsolete independently from the hardware, i.e. software encounters end of support dates that cause it to need to be replaced. Also, software obsolescence can be as a result of limited expertise knowledge or when support from the vendor terminates (Sandborn, 2007a). 
Table 1: Obsolescence criticality in the subsea production system

\begin{tabular}{lllll}
\hline Unit/equipment & \multicolumn{1}{c}{$\begin{array}{c}\text { Core } \\
\text { component }\end{array}$} & $\begin{array}{c}\text { Technology } \\
\text { evolution }\end{array}$ & $\begin{array}{c}\text { Replacement } \\
\text { alternatives }\end{array}$ & $\begin{array}{c}\text { Obsolescence } \\
\text { (risk) }\end{array}$ \\
\hline HPU & Electrical & Moderate & Less difficult & Low \\
EPU & Electrical & Moderate & Less difficult & Low \\
Umbilical and umbilical termination assembly & Mechanical & Low & Less difficult & Low \\
Electrical/hydraulic flying lead & Mechanical & Low & Less difficult & Low \\
Subsea booster pump & Mechanical & Moderate & Difficult & Moderate \\
Subsea separator & Mechanical & Moderate & Difficult & Moderate \\
Software & Programme & High & Less difficult & Moderate \\
Subsea control module & Electronics & High & Very difficult & Very high \\
\hline
\end{tabular}

The development of technologies able to provide solutions to increasing recovery and enhanced production is based on COTS equipment whose market and trend are not determined by the subsea market, but rather the communication, consumer and computer sector (Cretenet, 2004; Bartels et al., 2012). The effect is that manufacturers of these electronics are not interested in backward compatibility since the main demand for their products does not require this capability (Baker, 2011). This calls for obsolescence management strategy.

\section{Obsolescence management}

Obsolescence management involves all the activities, strategies and resolutions applied in addressing obsolescence issues. This includes managing factors that can increase cost resulting from shut-in period and addressing the unavailability of like-forlike replacements (British Standards Institution (BSI), 2007). It also determines the necessary actions for both the suppliers in the supply chain and the operators alike by applying risk management to reliability, rate of failure of component and obsolescence as related entities. Obsolescence management is concerned with reliability because obsolescence does not count except when the equipment fails (i.e. unreliability). Hence, this calls for the need to adopt a realistic strategy to manage obsolescence.

\subsection{Reactive and proactive strategy}

Addressing obsolescence issues can be treated following a reactive or proactive strategy (MacCormac,
2003). While the reactive strategy responds to obsolescence only when a failed component or equipment cannot be replaced, proactive strategy responds to obsolescence early before it occurs (BSI, 2007; Buratti and Brusco, 2000).

Each strategy has its own advantages and disadvantages, depending on the field life and the risk level involved. A reactive strategy may prove feasible where failure is unlikely and field life is low, e.g. 5 to 10 years (Baker, 2011; Energy Institute, 2011). However, a proactive strategy may be the best option where shut-in is unacceptable, as is the case for subsea production. The resolution methods for managing obsolescence for both proactive and reactive strategy are presented by different industries such as the military, the nuclear and the avionics industries (Shaw et al., 2010; Rojo, 2011; Tomczykowski, 2003; Shuman, 2002; Singh and Sandborn, 2006; Singh et al., 2002).

The non-recurring engineering (NRE) cost metrics for each of the resolutions produced by the US Department of Defense (DOD) survey prepared for the defence microelectronics activity (DMEA) are shown in the Table 2. The cost metrics find application in the subsea sector as it deals with a common electronic market, the former of which makes use of COTS in the latter's design of its microelectronics (Cretenet, 2004). The values for the NRE fiscal year 2012 are calculated based on the 1999 fiscal year inflation rate indices value of 1.37 (InflationData.com, 2012).

While the reactive strategy implies no particular budgetary provision for obsolescence management,

Table 2: Adopted resolution cost metrics from DMEA (Tomczykowski, 2001)

\begin{tabular}{lccc}
\hline Resolution & (By 1999) Mean (US\$) & (By 2012) Mean (US\$) & Weeks to resolve (Average) \\
\hline Existing stock & 0 & 0 & 0 \\
Reclamation & 1,884 & $2,581.08$ & 12 \\
Alternate source & 6,384 & $8,746.08$ & 11 \\
Substitute & 18,111 & $24,812.07$ & 25 \\
LOT buy & 43,684 & $59,847.08$ & 10 \\
Aftermarket manufacture & 47,360 & $64,883.2$ & 21 \\
Emulation & 68,012 & $93,176.44$ & 26 \\
Redesign minor & 111,034 & $152,116.58$ & 42 \\
Redesign major & 410,152 & $561,908.24$ & 64 \\
\hline
\end{tabular}


there can be significant consequential cost associated with subsequent unplanned remedial action. Proactive strategy, however, involves a budgetary provision which includes schedules of field life activity in the form of a call-off contract, which is awarded to a third party contractor to execute for the field operator (Tomczykowski, 2001).

\subsection{Obsolescence reduction through proactive strategy}

The BS EN 62402 (BSI, 2007) and the Ministry of Defence (2010) discuss five proactive strategy options: (1) design consideration, (2) technology transparency, (3) obsolescence monitoring, (4) planned system upgrade and (5) lifetime buy.

1. Design consideration: This strategy tries to minimise obsolescence issues by considering the following parameters: market and regulation, component selection, technology and reuse.

2. Technology transparency: This strategy depends on the open system architecture and specification of interfaces. It allows for technology insertion and backwards compatibility of the legacy system, thus making the system future proof to obsolescence or reducing the impact it will have caused.

3. Obsolescence monitoring: This approach involves tracking the processes, materials and components used in the product design, and taking actions necessary to address issues that may arise when any of them approach obsolescence.

4. Planned system upgrade: This option involves predetermining the point during which the system field life will be upgraded and obsolete component replaced. This is particularly applicable when many components are becoming obsolete as in a rapid technological development.

5. Lifetime buy: This involves purchasing the quantity of spares necessary to support the asset throughout the field life.

Generally, the advantage that a proactive strategy offers is that obsolete components are foreseen and resolved earlier before their failure. As a result, production losses are minimal compared to a reactive strategy. The upshot can be a huge saving in subsea production; however, it demands a budgetary provision and proper management for it to be properly executed.

\subsection{Context of the present study in subsea production}

Newer technologies have enabled the possibility of extending the field life of numerous brownfields feasibly through increased and enhanced oil recovery. The world's average recovery factor is just
$32-35 \%$ and thus the prospects of increasing recovery are attractive (Total, 2009; Tester, 2010). However, legacy control systems are not capable of supporting the new technologies and increased functionality. The SEM of the SCM is the most affected system because its core components are electronics being made of the fast evolving COTS sector. Loss production owing to failure of such equipment can make production undesirable; hence, the thrust of the present paper is concerned about implementing the right approach to obsolescence management.

The methodology presented in the present paper is based on defining the possible resolutions and strategies that can be deployed by the offshore oil and gas industry in managing obsolescence resulting from increased technological development. It then examines the resolutions applied in other industries, such as the avionics, nuclear and military industries.

Another solution involves the use of a cost approach in selecting the right strategy fit for subsea obsolescence management. This was achieved by using a DMSMS NRE resolution cost metrics survey executed by ARINC engineering services (AES), LLC, and DMEA for the DOD (for the military industry) and then adapting it for the subsea industry. This was based on the fact that the military DMSMS will not vary with the offshore oil and gas industry because they operate on the same electronic platform.

A further solution involves the use of the resolution cost metrics in evaluating the impact of the different obsolescence strategy (proactive and reactive) on the OPEX of a typical brownfield where technological development for increased oil recovery (IOR) has left the legacy control system obsolete. To achieve this, the Tordis field was chosen as a case study of a field that implemented, 13 years after first oil, a subsea separation boosting and injection (SSBI) system - a technology development for IOR.

Finally, the NRE cost metrics from the DOD was used to perform cost analysis to establish results on effective obsolescence strategy selection for a brownfield development.

\section{The Tordis field case study}

The Tordis field is located in block $34 / 7$ in the Tampen area of the Norwegian North Sea at a water depth of $200 \mathrm{~m}$ operated by Statoil. It came on stream in 1994 with additional developments Tordis East (1998) and Tordis South East (2001), and is tieback to the Gullfaks C platform $10 \mathrm{~km}$ away (Frantzen et al., 2011). 
The need for IOR in the Tordis field necessitated the implementation of the first SSBI system in 2007. Apart from the SSBI system, several new technological developments to improve field surveillance and reservoir monitoring were needed to enhance reliability, availability and throughput. Some of these components or equipment included sensors, capacitance hydrocarbon leak detectors, acoustic sand detectors, and acoustic hydrocarbon detectors. The power demand and high bandwidth exceeded the capacity of the legacy control system, which would have led to obsolescence if no action was taken.

\subsection{Limitation of the Tordis field control system before upgrade}

The legacy system has a low bandwidth communication capacity from subsea to surface with a bit rate of 1.2Kbits/s (Frantzen et al., 2011). This was severely inadequate when compared to the communication bandwidth required for the new technologies to be integrated. Along with these challenges, system integration was not possible because the legacy system was not designed from the outset to enable technological insertion through open system architecture.

The increased functionality expected in the Tordis field thus required a corresponding technological advancement in the control system, which needed to be capable of supporting the high power, high speed, increased data-handling capacity and reliability demand placed by the new technology. These new technologies include the SPU, intelligent well interface standardisation, subsea instrument interface standardisation and other sensor components for effective supervisory control and monitoring of the system. In addition, a control system capable of supporting technology insertions for the future was pertinent, so as to avoid the reoccurrence of the same problem in the future.

\subsection{Tordis obsolescence resolution and strategy implementation}

To keep the Tordis control system from obsolescence and in the right state of availability, the present paper will apply the different strategies discussed in section 3.1 using a cost approach. It is noted here that an upgrade of the control system should be the first approach and therefore must be implemented in the early design phase to enable the legacy system to a platform of the new requirements. It therefore will be considered as part of the capital expenditure (CAPEX). Subsequent obsolescence management technique will be analysed as part of OPEX.

\section{Cost analysis}

The analysis is based on the following data:

- IOR of the field is given as 35 million barrels;

- duration of field is estimated to be about 17 years;

- CAPEX for the field upgrade stands at US\$298 million.

\subsection{Assumptions taken for this calculation}

It is assumed that:

- oil price will remain steady at US\$80 per barrel throughout the field life;

- discount rate for the period is $18 \%$ and there is no redundancy in the system;

- budgetary provision for proactive strategy is \$US100,000 per year, required for the life cycle of the system that is more capital intensive in the earlier design phase;

- inflation is not considered during the field life;

- B-2 plane electronic size is equivalent to the Tordis field electronics size.

\subsection{Obsolescence cost impact on reactive strategy}

Applying the resolution cost metrics of Table 2 to a subsea obsolescence management will add value in implementing a reactive strategy. The cost implication for each resolution is calculated based on adapting the resolution cost metrics of the US Air Force B-2 Program base case analysis for a total of 21 B-2 airplanes for the period 1997 to 1999 (Tomczykowski, 2001). Therefore for a single B-2 plane, within a period of 17 years, the following resolutions were executed, as shown in Table 4.

For the subsea resolution cost analysis, it is assumed that the electronic size of a single B-2 is equivalent to the subsea electronics of the Tordis field. Therefore calculating for the reactive obsolescence field cost of each resolution, the following equations are applied together.

$$
\begin{aligned}
\text { Reactive obsolescence cost }= & \text { cost of loss oil production } \\
& + \text { field life cost of the } \\
& \text { given resolution }
\end{aligned}
$$

Cost of loss oil production $=$ production rate $(B O P D)$

$$
\begin{aligned}
& \times \text { duration (days) } \\
& \times \text { oil price }
\end{aligned}
$$

Using one of the resolutions (in this case 'substitute' as an example), then from Table 3 it is observed that the number of times the given resolution 'substitute' was used to resolve obsolescence issue for the field life is 3.5079365. Within the period of 
Table 3: Resolution occurrences during life of field

\begin{tabular}{lccc}
\hline Resolution & $\begin{array}{c}\text { Probability of } \\
\text { occurrence (\%) }\end{array}$ & $\begin{array}{c}\text { Number of resolutions } \\
\text { within 3 years for 21 B-2 } \\
\text { planes }\end{array}$ & $\begin{array}{c}\text { Number of resolutions } \\
\text { within 17 years for a } \\
\text { single B-2 plane }\end{array}$ \\
\hline Existing stock & 4.419889503 & 8 & 2.1587302 \\
Reclamation & 0 & 0 & 0 \\
Alternate source & 67.9558011 & 123 & 33.190476 \\
Substitute & 7.182320442 & 13 & 3.5079365 \\
LOT buy & 12.15469613 & 22 & 5.9365079 \\
Aftermarket manufacture & 4.972375691 & 9 & 2.4285714 \\
Emulation & 2.762430939 & 5 & 1.3492063 \\
Redesign minor & 0.552486188 & 1 & 0.2698413 \\
Redesign major & 0 & 0 & 0 \\
Total & 100 & 181 & 48.84127 \\
\hline
\end{tabular}

the field life, it is assumed that the resolution was implemented in years 4, 8, 12 and 16 .

$$
\begin{array}{r}
\left(\frac{(1 \times 24,812)+(13,123 \times 80 \times 25.5 \times 7)}{(1+0.18)^{4}}\right) \\
+\left(\frac{(1 \times 24,812)+(3,644 \times 80 \times 0.5 \times 7)}{(1+0.18)^{8}}\right) \\
+\left(\frac{(1 \times 24,812)+(2,752 \times 80 \times 0.5 \times 7)}{(1+0.18)^{12}}\right) \\
+\left(\frac{(0.5 \times 24,812)+(978 \times 80 \times 0.5 \times 7)}{(1+0.18)^{16}}\right) \\
=\mathrm{US} \$ 97,077,241
\end{array}
$$

where:

- $\left(\frac{1}{(1+0.18)^{\mathrm{Y}}}\right)$ represents discount factor for the respective years with an $18 \%$ discount rate.

- US $\$ 24,812$ is the substitute resolution cost for each occurrence.

- 13,123BOPD, 3,644BOPD, 2,752BOPD, 978BOPD represents estimated production profile of the field at years 4, 8, 12 and 16, respectively. (US\$80 is the average price per barrel.)

- 25.5 weeks represents the total time in weeks for substitute resolution and time spent for installation. This takes place only for the first substitute resolution implementation.

- 0.5 weeks represent time for installation and 7 represents number of days in a week (see appendix 1 and 1.1 for details).

The procedure is applied for the different resolutions and the result is as shown in Table 4 .

The total cost using a reactive approach is calculated as approximately equal to US $\$ 433$ million (see appendix 1 for details). Fig 4 represents the comparison of the different resolutions as adapted for the Tordis field reactive resolution strategy.
Table 4: Individual resolution costs for reactive approach

\begin{tabular}{lc}
\hline Resolution & Cost (Million US\$) \\
\hline Existing stock & 1.036190476 \\
Reclamation & 0 \\
Alternate source & 53.18171513 \\
Substitute & 85.77084869 \\
LOT buy & 36.80480647 \\
Aftermarket manufacture & 71.88328777 \\
Emulation & 88.13333329 \\
Redesign minor & 141.2905711 \\
Redesign major & 0 \\
Total & 478.100753 \\
\hline
\end{tabular}

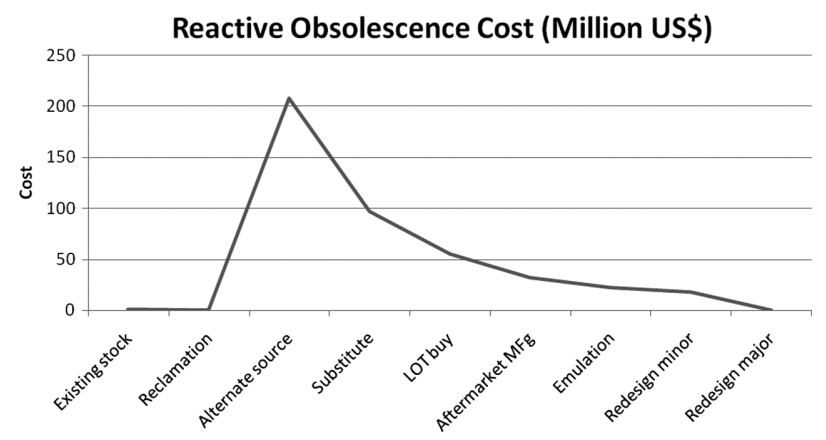

Fig 4: Reactive strategy field life resolution cost impact

\subsection{Obsolescence cost impact on proactive strategy}

The costing for a proactive strategy for the field is achieved by following a similar approach as used in the reactive obsolescence cost calculation. However, the cost of loss production in resolution implementation is reduced drastically to $6 \%$, as resolutions are proactively executed before the failures occur.

While in the case of reactive strategy no budgetary cost is set aside, proactive strategy sets aside a yearly contract sum of US $\$ 100,000$ which is equivalent to US $\$ 1.7$ million for the 17 -year period to improve the effectiveness of proactive strategy. Table 5 shows the field life cost of each resolution. 
Table 5: Individual resolution costs for proactive approach

\begin{tabular}{lc}
\hline Resolution & $\begin{array}{c}\text { Cost } \\
\text { (Million US\$) }\end{array}$ \\
\hline Existing stock & 1.036190476 \\
Reclamation & 0 \\
Alternate source & 16.22171513 \\
Substitute & 1.77084869 \\
LOT buy & 3.204806475 \\
Aftermarket manufacture & 1.323287771 \\
Emulation & 0.773333292 \\
Redesign minor & 0.170571141 \\
Redesign major & 0 \\
Contract sum for proactive management & 1.7 \\
Total & 26.20075298 \\
\hline
\end{tabular}

The total cost using a proactive approach on Tordis is calculated as approximately equal to US $\$ 146$ million (see appendix 2 and 2.1 for details).

Fig 5 represents the comparison of the different resolutions as adapted for the Tordis field case study.

\subsection{Comparison of proactive and reactive resolution strategies}

A comparison of the resolution cost metrics for the two strategies is represented in Fig 6. It signifies that the major resolution cost lies in the redesign. Hence proper management is required to mitigate it by being proactive.

\subsection{Obsolescence management cost and field OPEX}

\subsubsection{Revenue calculation}

The revenue for the field was calculated according the equation given below.

$$
\text { Revenue }=\text { recoverable reserve } \times \text { price of oil }
$$

where recoverable reserve $=35$ million barrels, and price of oil per barrel $=\$ 80$. Hence the revenue for 17 years of extended field life will cost US\$2.8 billion.

\subsubsection{OPEX calculation}

The Tordis field OPEX was calculated based on Equation 5:

$$
\begin{aligned}
\text { Total OPEX }= & \text { total fixed cost } \\
& + \text { total variable cost }+ \text { total obsolescence cost } \\
& + \text { decommissioning cost }
\end{aligned}
$$

(Note: total variable cost used in this equation represents the variable cost less obsolescence cost resolution. It is based on a field first year variable cost, that is, obsolescence is minor or does not exist.)

Therefore, assuming a fixed cost of US\$8 million per year, a variable cost of US $\$ 10$ per barrel and a

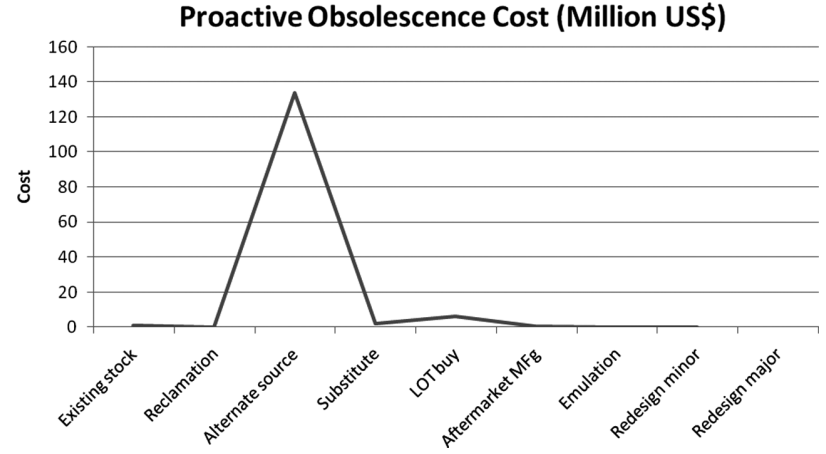

Fig 5: Proactive strategy field life resolution cost impact

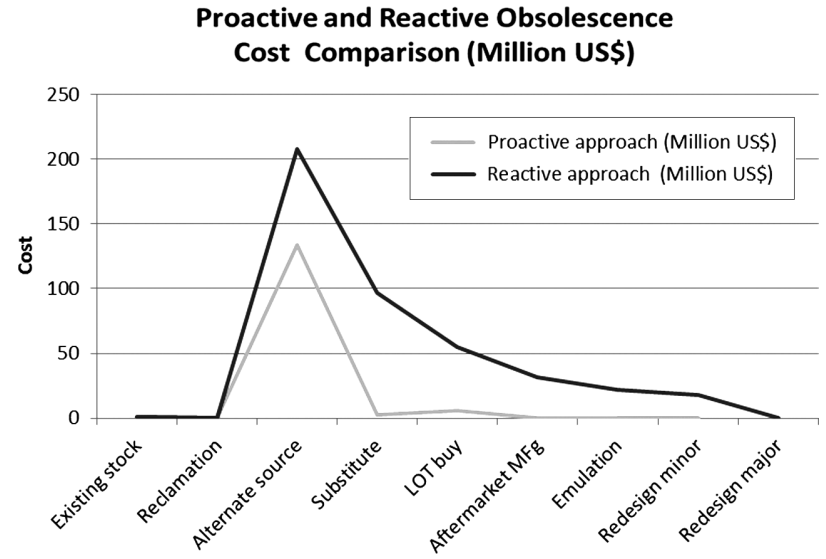

Fig 6: Comparison of proactive and reactive strategies obsolescence management cost in the Tordis field case study

decommissioning cost of US $\$ 5$ million (Abili et al., 2012), total OPEX of field for a reactive strategy in obsolescence management is calculated as:

$$
\begin{aligned}
& (\$ 8 \text { million per year } \times 17 \text { years }) \\
& +(\$ 10 \text { per barrel } \times 35 \text { million barrel }) \\
& +\$ 433 \text { million }=\text { US } \$ 919 \text { million }
\end{aligned}
$$

where $\$ 433$ million is the reactive resolution cost of the field for the 17-year period. In addition, the total OPEX of field for proactive strategy is calculated as:

$$
\begin{aligned}
& (\$ 8 \text { million per year } \times 17 \text { years }) \\
& \quad+(\$ 10 \text { per barrel } \times 35 \text { million barrels }) \\
& +\$ 146 \text { million }=\mathrm{US} \$ 632 \text { million }
\end{aligned}
$$

where $\$ 146$ million is the proactive resolution cost of the field for the 17-year period.

To calculate the total expenditure:

$$
\begin{aligned}
\text { Total expenditure }= & \text { total CAPEX }+ \text { total OPEX } \\
& + \text { decommissioning }
\end{aligned}
$$

where the total CAPEX from the Tordis SSBI award is US\$298 million, and decommissioning cost is $\$ 5$ million. Therefore, total expenditure for the reactive and proactive approach stands at US\$1.222 billion and US\$935 million, respectively. (Note: calculation is 
made based from the time of investment of SSBI to end of field life.)

\subsubsection{Profit}

The profit is derived based on the folloiwng equation:

$$
\text { Profit }=\text { revenue }- \text { total expenditure }
$$

Therefore profit before tax for the system that uses reactive approach is:

$$
\$ 2.8 \text { billion }-\$ 1.222 \text { billion }=\text { US } \$ 1.578 \text { billion }
$$

The profit before tax for the system that uses a proactive approach is:

$$
\$ 2.8 \text { billion }-\$ 935 \text { million }=\text { US } \$ 1.865 \text { billion }
$$

\section{Discussion and analysis}

Considering the two obsolescence management strategies in subsea development, the reactive strategy stands at US $\$ 433$ million while the proactive strategy stands at US $\$ 146$ million. The proactive cost in this case study is approximately three times less than the reactive cost. These costs have direct impact on the profit before tax of the field, which stands at $\$ 1.578$ billion and $\$ 1.865$ billion for the reactive and proactive approaches, respectively. The profit difference in the two approaches is approximately the CAPEX investment of SSBI. Thus, owing to return of investment on field developments, these resolution strategies examined in the present paper from a cost perspective will be applicable profitably to offshore operators.

\subsection{Availability improvement}

Applying a proactive strategy over a reactive strategy resulted in improved availability of 945 days on the field life of the case study, as deducted from the total weeks to resolve installation time in appendices 1 and 2. If a reactive approach were applied, this would have resulted in a huge loss of revenue. Thus, the result shows that a reactive approach is not appropriate to a subsea facility, particularly for extended years of field development. However, the only exceptions can be in situations where: (1) the field life is very short; (2) there are no opportunities for further development; (3) the probability of obsolescence is very low; (4) there are dependable OCM guarantees; and (5) the product is dependable and can be supported throughout the field life.

\subsection{Further benefit of proactive management}

In further mitigating obsolescence issues proactively through the given resolution methods presented in the present paper, the potential benefits of a proactive strategy are felt most when it is applied at the early design phase through technology transparency (open architecture) and obsolescence monitoring (Mackenzie, 2011; Jones and Seabridge, 2010; Jones, 1995). Some features to consider when applying a proactive strategy during the early design phase are as follows:

- Plug and play - With an open architecture system, interface development and testing costs are reduced, and this allows new equipment or components to be easily integrated into the existing system (Mackenzie, 2011).

- High bandwidth - Using a fibre-optic platform allows for increased bandwidth and thus can provide communication links with high bandwidths in the region of Gigabit/seconds. This high-speed link allows real-time data acquisition which includes diagnostic data from both existing subsea sensors and newly integrated sensors with capacity for video streaming, fibre-optic leak detection, etc. (Mackenzie, 2011; Holley, 2010).

- Expandability - The benefits of an open system allow for pre-installation of mechanical and electrical interfaces in preparation for future sensor installations. This flexibility enables the procurement of the subsea monitoring and control equipment without prior need for upfront information about the final sensor requirements and interfaces (Mackenzie, 2011; Henderson, 2009).

- Reduced whole life cost - This is the benefit for a greenfield where the open architecture system is employed in the early phase design concept selection. The system cost, which would have been incurred owing to difficulties in technology insertion alongside component replacement resulting from obsolescence throughout the whole life of the field as it experiences evolutionary changes, are significantly reduced (Henderson, 2009).

\section{Conclusion}

The present paper has evaluated the strategies established in other industrial sectors to address obsolescence in the subsea oil and gas industry, with a focus on electronics for the subsea controls system. A case study was carried out on a typical brownfield development which has demonstrated that while a reactive approach to obsolescence management in a subsea facility can be very risky and costly, a proactive strategy is more appropriate and less expensive with respect to the OPEX.

Employing a cost approach for the two different strategies on the Tordis SSBI on a brownfield development, the results show the cost of a proactive 
approach is less by US $\$ 287$ million than a reactive approach, which is an incentive for the IOR technique. In addition, the present paper demonstrates the major downside to a reactive approach as the loss of production owing to the shut-in period proves to be very costly and undesirable.

It is important to note that electronic obsolescence is unavoidable, but an implementation of proactive strategy in the early design phase through open architecture and modular structure has the ability of reducing impact of component obsolescence. However, system upgrade is a vital key for obsolescence management of legacy controls systems, as technological developments, such as subsea processing, place high demand on power, bandwidth and functionality, which allows for improved availability during the extended field life for brownfields. The offshore industry will benefit significantly in applying obsolescence management strategy economically on subsea field developments in meeting the high evolutionary demands placed on the OCMs and OEMs.

\section{Acknowledgement}

The authors wish to express gratitude to all the resources accredited to the present paper. Special thanks is given to Cranfield University for its support on this work carried out within its facilities.

\section{References}

Abicht D and Akker JVD. (2011). The 2nd generation DC all-electric subsea production control system. Offshore Technology Conference, 2-5 May, Houston, Texas, Paper No. OTC 21300-MS

Abili N, Udofot O and Kara F. (2012). Subsea processing - a holistic approach to marginal field developments. Underwater Technology 30: 167-176.

Adrain P. (2008). West of Shetland: new frontiers and legacy systems. Presented at Subsea Seminar - Securing a safe and sustainable future for subsea, Oil and Gas Subsea series, Aberdeen, UK. Available at www.oilandgasuk. co.uk/downloadabledocs/818/b11.\%20Adr, last accessed $<18$ June 2012>.

Aker Kvaerner. (2005). Developing an obsolescence management plan. Presented at Obsolescence Management Impact and Implementation of Obsolescence Issues in Subsea, SUT evening meeting series, Aberdeen, UK. Available at http://pastevents.sut.org.uk/2005/050914/ DerekRobertson.pdf, last accessed $<13$ May 2012>.

Aker Solutions. (2009). Managing obsolescence and new technology requirement. Presented at Advancements in Subsea Control Systems Technology, SUT technical meeting series, Perth, AU. Available at www.sut.org.au/perth/perth_ events/Aker_Solutions_Low_power_SEM_managing obsolescence_060809.pdf, last accessed <12 May 2012>.

Baker JHA. (2011). Integrating reliability, obsolescence and integrity management into life cycle management of subsea facilities. Underwater Technology 30: 35-41.
Bartels B, Ermel U, Pecht M and Sandborn P. (2012). Strategies to the Prediction, Mitigation and Management of Product Obsolescence. Hoboken, NJ: John Wiley \& Sons, Inc., 288pp.

Beedle A and Stansfield J. (2010). Current trends and design limitations of subsea control hardware. Offshore Technology Conference, 3-6 May, Houston, Texas, Paper No. OTC 20633-MS.

British Standards Institution (BSI). (2007). BSEN 62402:2007 Obsolescence Management - Application Guide. London: British Standard Institution.

Broadbent PA. (2010). Controls reliability and early life of field failure of subsea control modules. In: Subsea Control and Data Acquisition: Future Technology, Availability and Through Life Challenges. Paper No. SUT SCADA-10-31. London: Society for Underwater Technology, 31-38.

Buratti M and Brusco D. (2000). The obsolescence management based on a 'pro-active' approach in conjunction with a 'pre-planned' technology insertion route. Strategies to Mitigate Obsolescence in Defense Systems Using Commercial Components, 23-25 October, Budapest, Hungary, Research and Technology Organisation, Paper No. RTO MP-072. France: Research and Technology Organization, NATO.

Cahill J. (2009). Component obsolescence and its impact on electronic industries. Available at: www.tachustech.com/ images / uploaded_images/1252737424Component\% 20Obsolescence $\% 20$ and $\% 20$ its $\% 20$ impact $\% 20$ on $\% 20$ electronic\%20industries.pdf, last accessed $<12$ May 2012>.

Chiesa G and Eriksen R. (2000). Subsea processing - the solution to cost efficient deepwater field developments. Offshore Technology Conference, 1-4 May, Houston, Texas, Paper No. OTC 11892-MS.

Condra LW, Anissipour AA, Mayfield DD and Pecht, MG. (1997). Electronic components obsolescence. IEEE Transactions on Components, Packaging and Manufacturing Technology 20: 368-371.

Cretenet A. (2004). Obsolescence of electronics potential impact on subsea control from an operator's standpoint. In: Adriaansen L (ed.). Subsea Control and Data Acquisition: Experience and Challenges. London: Wiley-Blackwell, 55-60.

Department of Energy and Climate Change. (2012). Historical production data: complete production history for oil fields (from 1975) and gas fields (from 1995) to date. Available at https://www.gov.uk/oil-and-gas-uk-fielddata, last accessed $<17$ September 2013 $>$.

Energy Institute. (2011). Guidelines for the Management of Obsolescence in Subsea Facilities. London: Energy Institute.

Feldman K and Sandborn P. (2007). Integrating technology obsolescence considerations into product design planning. Proceedings of the 2007 ASME International Design Engineering Technical Conferences and Computers and Information in Engineering Conference, 4-7 September 2007, Las Vegas, Nevada, vol. 4.

Frantzen KH, Kent I and Phillips R. (2011). Control system upgrades for Tordis and Vigdis field - a project case study of revitalising Brownfield developments with next generation subsea controls. Offshore Technology Conference, 2-5 May, Houston, Texas, Paper No. OTC 21786.

Gall G, Turner P and Seaton R. (2002). Reliability of subsea control systems: HIPPS a case Study. Subsea Controls and Data Acquisition 2002. Paper No. SUT-SCADA-02-055. London: Society for Underwater Technology, 16pp.

Henderson P. (2009). The case for open systems architecture. Available at http://pmh-systems.co.uk/Papers/ MOSACaseFor/, last accessed $<7$ August 2012>. 
Holley S. (2010). New subsea electronic module offers enhanced communications. Hart's E E P 83: 77-78.

InflationData.com. (2012). Inflation rate calculator. Available at: http://inflationdata.com/Inflation/Inflation Calculators/Inflation_Rate_Calculator.asp, last accessed $<4$ August 2012>.

Jones D and Seabridge A. (2010). Managing obsolescence in the aircraft life cycle. In: Blockley R and Shyy W (eds.). Encyclopedia of Aerospace Engineering. New York: John Wiley \& Sons, Inc.

Jones JW. (1995). Subsea production systems - trends in the nineties. Offshore Technology Conference, 1-4 May, Houston, Texas, Paper No. OTC 7866-MS.

Josias C, Terpenn JP and McLean KJ. (2004). Component obsolescence risk assessment. IIE Annual Conference and Exhibition 2004, 15-19 May, Houston, Texas, Institute of Industrial Engineers, 2373-2378.

Lewis J, Macleod A and Gallacher M. (2009). Control and safety system (ESD, F\&G and PCS) obsolescence, a practical solution for system migration taking account of aging facilities while maintaining safety standards. SPE Offshore Europe Oil and Gas Conference, 8-11 September, Aberdeen, UK, Society of Petroleum Engineers, Richardson, Texas, Paper No. SPE 124237-MS.

MacCormac P. (2003). Getting proactive in the fight against obsolescence. Engineering Technology 6: 28.

Mackenzie R. (2011). Controlling tomorrow's subsea technology: providing increased system functionality and embracing obsolescence management. Presented at Deep Offshore Technology Conference, 11-13 October, New Orleans, Louisiana.

McClimans OT and Fantoft R. (2006). Status and new developments in subsea processing. Offshore Technology Conference, 1-4 May, Houston, Texas, Paper No. OTC 17984-MS.

McDermott J, Shearer J and Tomczykowski W. (1999). Resolution cost factors for diminishing manufacturing sources and material shortages. Final report, contract no. GS-35F-4825G. Annapolis, MD: ARINC.

Midttveit S, Monsen B, Frydenlund S and Stenevik K. (2010). SS on Implications of subsea processing power distribution - subsea power systems - a key enabler for subsea processing. Offshore Technology Conference, 3-6 May, Houston, Texas, Paper No. OTC 20621-MS.

Ministry of Defence. (2010). The defence logistics support chain manual: obsolescence management. JSP 886, vol. 7, part 8.13. London: Ministry of Defence.

Neri R and Falk K. (2006). Subsea architectures to facilitate increased recovery from reservoirs: Subsea processing, condition monitoring and process optimisation in a modern subsea control system. In: Subsea Control and Data Acquisition: Controlling the Future Subsea. Paper No. SUT-SCADA-06-141. London: Society for Underwater Technology, 9pp.

Rasmussen AW. (2003). Enhanced oil recovery by retrofitting subsea processing. Offshore Europe, 2-5 September, Aberdeen, UK, Society of Petroleum Engineers, Richardson, Texas, Paper No. SPE 83976-MS.

Rojo F. (2011). Development of a framework for obsolescence resolution cost estimation (PhD thesis), Cranfield University, UK
Sandborn P. (2007a). Software obsolescence - Complicating the part and technology obsolescence management problem. IEEE Transactions on Components and Packing Technologies 30: 886-888.

Sandborn P. (2007b). Designing for technology obsolescence management. In: Bayraksan E, Lin W, Son Y and Wysk R (eds.). Proceedings of the 2007 Industrial Engineering Research Conference, 1684-1689.

Saul D. (2006). The need to adopt a proactive approach to obsolescence management in subsea controls. In: Subsea Control and Data Acquisition: Controlling the Future Subsea. Paper No. SUT SCADA-06-005. London: Society for Underwater Technology, 12pp.

Shaw W, Speyere F and Sandborn P. (2010). Diminishing manufacturing sources and material shortages (DMSMS) non-recurring engineering (NRE) cost metric update. Final report, contract no. H94003-10-F-0109. Annapolis, MD: ARINC Engineering Services.

Shearer J and Tomczykowski W. (2001). Resolution cost metrics for diminishing manufacturing sources and material shortages. Supplemental report, contract no. GS-35F-4825G. Annapolis, MD: ARINC.

Shuman LM. (2002). Cost benefit analysis tools for avionics parts obsolescence (Msc thesis), Maxwell Air Force Base Alabama. Available at www.dtic.mil/cgi-bin/ GetTRDoc?AD $=$ ADA420530, last accessed $<5$ July 2012 $>$.

Singh P and Sandborn P. (2006). Obsolescence driven design refresh planning for sustainment dominated systems. The Engineering Economist 51: 115-139.

Singh P, Sandborn P, Lorenson D and Geiser T. (2002). Determining optimum redesign plans for avionics based on electronic part obsolescence forecasts. Warrendale, PA: Society of Automotive Engineers. Available at www.enme.umd.edu/ESCML/Papers/02WAC-150.pdf, last accessed $<15$ July 2012 $>$.

Solomon R, Sandborn P and Pecht M. (2000). Electronic part life cycle concepts and obsolescence forecasting. IEEE Transactions on Components and Packing Technologies 23: 707-717.

Tester R. (2010). Solutions for improved operational efficiencies and enhanced oil recovery by mid-life technology insertion into older fields. In: Subsea Control and Data Acquisition: Future Technology, Availability and Through Life Challenges. Paper No. SUT SCADA-10-107. London: Society of Underwater Technology, 107-114.

Tomczykowski W. (2001). DMSMS Acquisition guidelines: Implementing parts obsolescence management contractual requirements, Rev 3. Contract no.: DMEA90-00-F-0003. Annapolis, MD: ARINC. Available at: www.dmea.osd.mil/ docs/acquisition_guidelines.pdf, last accessed $<4$ August 2012>.

Tomczykowski WJ. (2003). A study on component obsolescence mitigation strategies and their impact on R\&M. The International Symposium on Product Quality and Integrity; Transforming Technologies for Reliability and Maintainbility Engineering, 27-30 January, Tampa, Florida, IEEE Reliability Society, 332-338.

Ward CD and Sohns CW. (2011). Electronic component obsolescence. IEEE Instrumentation and Measurement Magazine 14: 8-12. 


\section{Appendices}

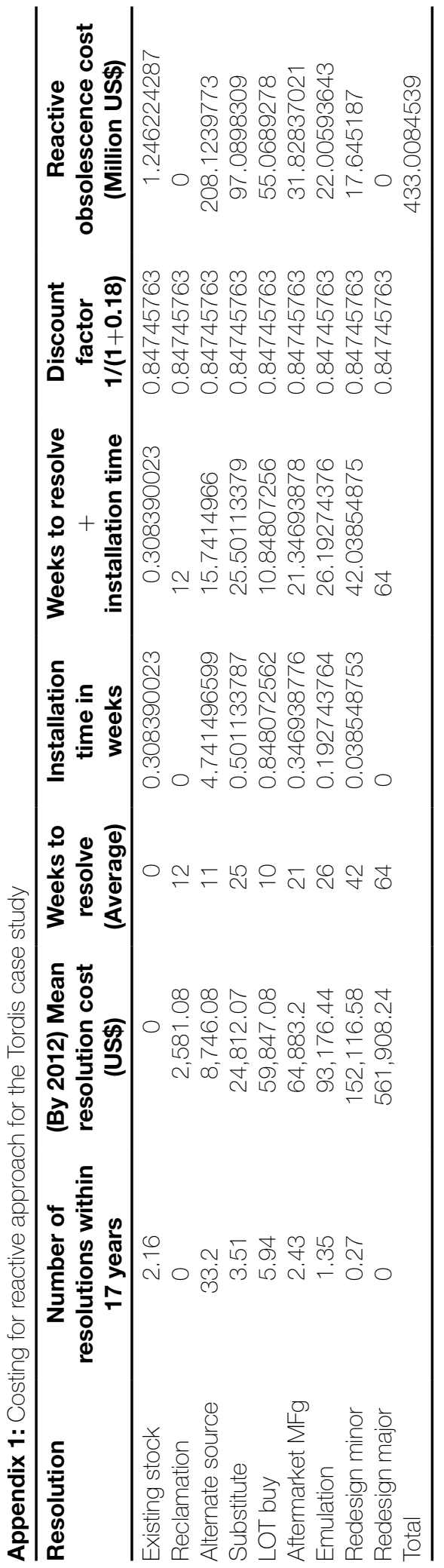




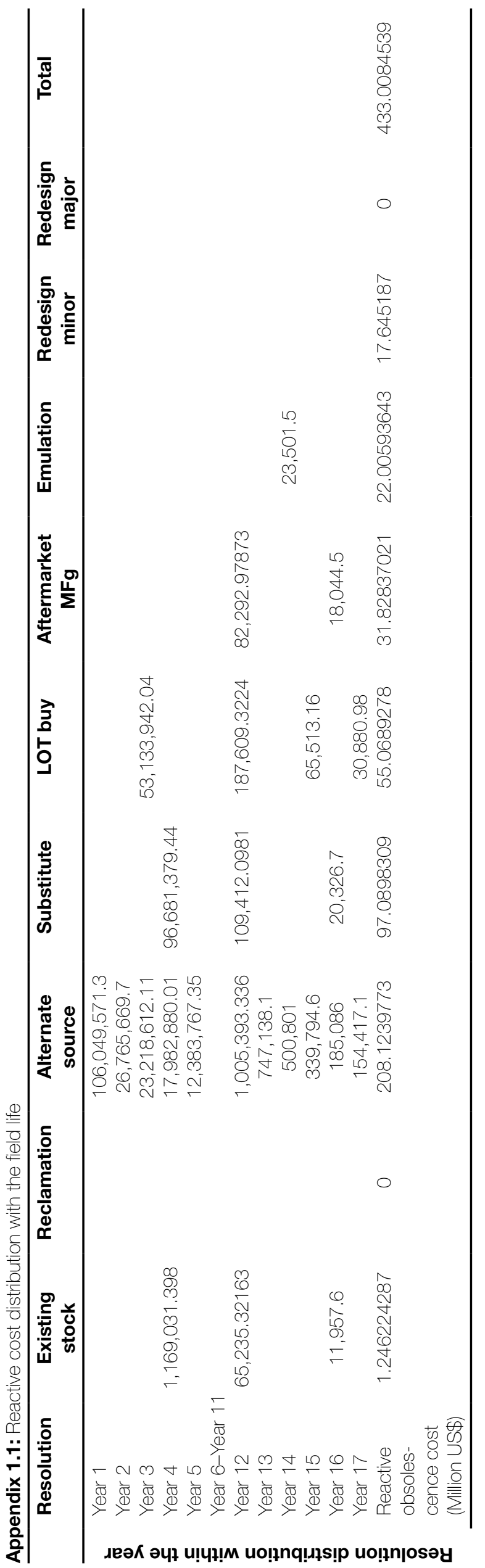




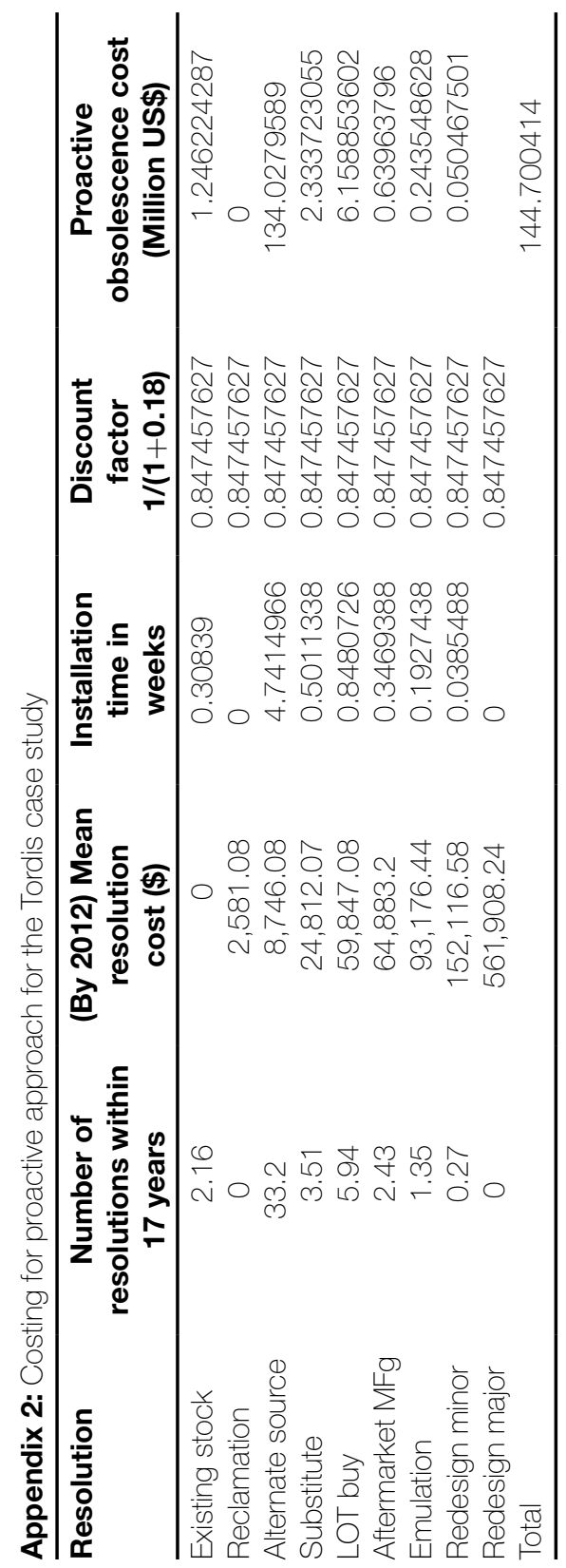




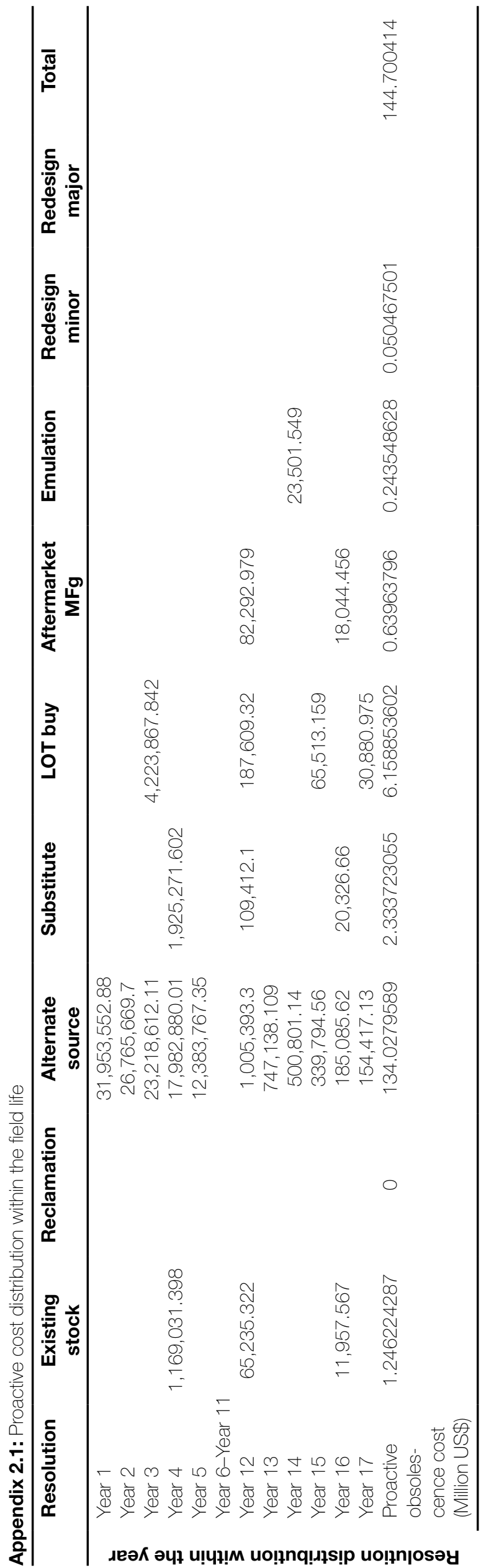

